\title{
Monolithic Silica Capillary Columns with Improved Retention and Selectivity for Amino Acids
}

\author{
Dana Moravcová * and Josef Planeta \\ Czech Academy of Sciences, Institute of Analytical Chemistry, Veveri 97, Brno 60200, Czech Republic; \\ planeta@iach.cz \\ * Correspondence: moravcova@iach.cz; Tel.: +42-053-229-0218
}

Received: 27 June 2018; Accepted: 5 September 2018; Published: 2 October 2018

\begin{abstract}
A strategy for the preparation of silica-based monolithic capillary columns $(150 \times 0.1 \mathrm{~mm})$ with high selectivity to amino acids is presented. The zwitterionic columns were prepared by coating the silica monolith with [2-(methacryloyloxy)ethyl]-dimethyl-(3-sulfopropyl)-ammonium hydroxide via 3-(trimethoxysilyl)propyl methacrylate. The columns were evaluated under isocratic conditions in hydrophilic interaction liquid chromatography. The best separation of amino acids was obtained on the monolithic column prepared by a stepwise modification procedure where the modification step was repeated four times. The mixture of fifteen amino acids was separated within 13 min using the mobile phase consisting of $75 \%$ acetonitrile and $25 \% 5 \mathrm{mmol} / \mathrm{L}$ ammonium acetate at $\mathrm{pH} 4.5$.
\end{abstract}

Keywords: HILIC; amino acids; silica monolithic column

\section{Introduction}

Analysis of amino acids has become an important task in different areas of life sciences such as foodomics, proteomics, metabolomics, and biopharmaceuticals, where accurate, precise, and robust amino acid analyses are required [1-5]. Liquid chromatography (LC) is widely utilized to determine the content of amino acids in samples. These are usually determined after the chemical derivatization, which improves their chromatographic behavior or increases their detection sensitivity by ultra violet (UV), fluorescence, or mass spectrometric (MS) detection [6]. LC analysis of native amino acids has become ever more popular due to the availability of highly-sensitive MS detection. The gradient or multi-gradient elution conditions are used in hydrophilic interaction chromatography (HILIC) or reversed-phase chromatography (RPLC) to resolve complex mixtures of native amino acids or their derivatives [1-5,7]. The weakness of this approach is the need for re-equilibration of the system to initial conditions, which increases the total time of analysis. If a large number of samples is analyzed, avoiding the gradient elution could be of significant benefit, because of increased sample throughput and reduced solvent consumption.

Capillary liquid chromatography is a highly popular and widespread separation technique in laboratories working in the research areas of pharmacology, proteomics, and metabolomics. Moreover, many reviews published in recent years summarize trends in the design and evaluation of instruments suitable for capillary and nano-liquid chromatography [8-13].

The most important part of the LC system is the chromatographic column, which enables successful resolution of complex samples containing a large number of components. The particle-packed capillary columns available on the market are packed with the same sorbents as columns of analytical dimensions. Thus, a wide range of packed capillary columns is available. On the other hand, the supply of monolithic capillary columns is limited to columns suitable for RPLC, such as the polymer-based ProSwift ${ }^{\mathrm{TM}}$ monolithic LC columns, supplied by Thermo Scientific ${ }^{\mathrm{TM}}$ (Waltham, MA, USA), the silica-based monolithic columns Chromolith ${ }^{\circledR}$ CapRod $^{\circledR}$ 
capillary LC columns, supplied by Merck KGaA (Darmstadt, Germany), Onyx ${ }^{\mathrm{TM}}$ Monolithic C18 column supplied by Phenomenex (Torrance, CA, USA), and, last but not least, a company offering silica-based monolithic columns is GL Sciences Inc. (Tokyo, Japan) with MonoCap series of columns suitable for RPLC, HILIC, and strong-cation-exchange chromatography. Along with an ever-expanding supply of monolithic columns, new monolithic materials which are suitable for highly-specialized separations are being prepared in laboratories around the world [14-18].

However, the conventional RPLC columns, as well as other recently introduced, specialized columns, are not suitable for the isocratic LC separation of underivatized amino acids. Therefore, the presented study is focused on the preparation of zwitterionic silica-based monolithic capillary columns suitable for the isocratic HILIC separation of native amino acids.

The concept for the synthesis of silica-based monolithic columns was published by Nakanishi and coworkers in the early 1990s $[19,20]$. The first silica monoliths were prepared by acidic hydrolysis of tetramethoxysilane (TMOS), or mixture of TMOS and methyltrimethoxysilane. An appropriate stationary phase was obtained by a chemical postmodification procedure [21]. Later, various alkyltrialkoxysilanes and their mixtures with alkoxysilanes or organic monomers were utilized to synthesize silica-based monolithic capillary columns [22].

Our monoliths were prepared by acidic hydrolysis of TMOS in the presence of polyethylene glycol and urea. The plain silica monolith was then modified by 3-trimethoxysilylpropyl methacrylate ( $\gamma$-MAPS) to introduce vinyl groups to the monolithic silica surface. Thermally-initiated free radical polymerization was applied to create a polymer coating of zwitterionic [2-(methacryloyloxy)ethyl]-dimethyl-(3-sulfopropyl)-ammonium hydroxide (MSA) on the silica surface. MSA is a commercially-available substance which is frequently used for the synthesis of monolithic columns. Preparation and LC characterization of the first polymer-based monoliths containing MSA suitable for ion-exchange chromatography of proteins and purification of peptides was published by Viklund et al. [23]. MSA capillary monoliths were prepared a few years later, and evaluated under HILIC conditions for separation of polar compounds such are neutral acrylamides, benzoic acid derivatives, and nucleobases [24]. MSA monoliths show a multimodal retention mechanism due to the nature of the MSA monomer. Urban et al. [25] investigated the transition between RPLC and HILIC mechanisms on monoliths prepared from a mixture of MSA and ethylene dimethacrylate.

Silica monolithic capillary columns prepared from TMOS and modified to a sulfobetaine type zwitterionic stationary phase were used for site-specific glycosylation analysis by Wohlgemuth et al. [26] and for separation of nucleobases and nucleosides under isocratic and gradient HILIC conditions [27]. Lin et al. utilized MSA as a part of the polymerization mixture for the preparation of monolithic capillaries by a "one-pot" approach. Benzoic acid derivatives, phenols, purines and pyrimidines, and nucleosides were used to evaluate the prepared columns under HILIC conditions [28].

\section{Materials and Methods}

\subsection{Chemicals and Reagents}

Ammonium acetate, acetic acid, acetonitrile (ACN, LC/MS-grade), [2-(methacryloyloxy)ethyl]-dimethyl-(3-sulfopropyl)-ammonium hydroxide, toluene, absolute ethanol, methanol, sodium hydroxide, hydrochloric acid (p.a.), azobisisobutyronitrile (AIBN), xylene mixture of isomers (Product \#: 95690), 3-trimethoxysilylpropyl methacrylate ( $\gamma$-MAPS), and all standard compounds used were purchased from Sigma-Aldrich (Austria). Water purified with a Milli-Q A10 Gradient (Millipore, Burlington, MA, USA) was used in the experiments. 


\subsection{Instrumentation}

The equipment used for LC-UV consisted of a syringe pump (100 DM with D-series controller, Teledyne Isco, Lincoln, NE, USA), an electrically actuated E90-220 injection valve with a $60 \mathrm{~nL}$ or $500 \mathrm{~nL}$ inner loop (Valco, Houston, TX, USA), and a T-splitter with a restrictor (fused silica capillary $0.025 \mathrm{~mm}$ i.d. $\times 150 \mathrm{~mm}$ length). The monolithic column outlet was connected to a Spectra $100 \mathrm{UV}$-Vis detector (Thermo Separation Products, Waltham, MA, USA) via a fused silica capillary of dimensions $0.035 \mathrm{~mm}$ i.d. $\times 110 \mathrm{~mm}$, with a bubble cell optical window $(0.110 \mathrm{~mm}$ i.d.) made by controlled etching. The geometrical volume of this connecting capillary was $0.106 \mu \mathrm{L}$. UV-detection was performed at $210 \mathrm{~nm}$. Data were collected and processed using DataApex Clarity 5.02 software.

\subsection{Preparation of Monolithic Capillary Columns}

Plain monolithic silica-based capillary columns were prepared by acidic hydrolysis of TMOS in the presence of polyethylene glycol (molar mass of 10,000) and urea, and modified by $20 \%(v / v)$ of $\gamma$-MAPS in $95 \%(v / v)$ ethanol containing $5 \%(v / v)$ of acetic acid and water $(1: 1)$. The preparation protocol was outlined in our previous study [29]. Columns were flushed with absolute ethanol, dried under a stream of nitrogen at $25^{\circ} \mathrm{C}$ for $6 \mathrm{~h}$, and then used for further modification to the zwitterionic stationary phase.

A mixture of methanol $(30 \%, v / v)$ and xylenes $(70 \%, v / v)$ was employed as the solvent in the grafting mixture. AIBN at concentration of $3 \mathrm{wt} . \%$ proportionally to monomer MSA $(60 \mathrm{mg} / \mathrm{mL})$ was used to initiate the polymerization reaction. The MSA coating was created on the silica monolith as follows: The capillary column modified by $\gamma$-MAPS was flushed by a solution of MSA at $25^{\circ} \mathrm{C}$ and a flow rate of $0.5 \mu \mathrm{L} / \mathrm{min}$ for $20 \mathrm{~min}$. The ends of the column were sealed by the septum and static modification proceeded at $80{ }^{\circ} \mathrm{C}$ for $1.5 \mathrm{~h}$. Then, the column was extensively flushed by a mixture of methanol and xylenes, by pure methanol, and finally by a mixture of ACN and the acetate buffer to remove remaining MSA homopolymers out of the column. The column was shortened to $150 \mathrm{~mm}$ and evaluated under HILIC conditions using toluene and uracil as a sample. The modification procedure mentioned above was repeated (1-4 times) to prepare monolithic capillaries with improved retention of analytes and selectivity of the stationary phase as discussed below. The capillary column was extensively flushed by a mixture of $70 \% \mathrm{ACN} / 30 \%$ water, dry methanol, and dried under the stream of nitrogen at $25^{\circ} \mathrm{C}$ for $3 \mathrm{~h}$ before the creation of the next MSA coating layer on the monolithic stationary phase.

\subsection{Preparation of Mobile Phases and Sample Solutions}

The premixed mobile phase consisted of $70 \% \mathrm{ACN}$ and $30 \%$ ammonium acetate buffer $\mathrm{pH} 4.5$ at the concentration of 5 or $25 \mathrm{mmol} / \mathrm{L}$.

The sample solution was prepared in $70 \% \mathrm{ACN}$ and $30 \% 5 \mathrm{mmol} / \mathrm{L}$ ammonium acetate at $\mathrm{pH}$ 4.5. Because of the UV-detection and nature of analytes, the sample mixture for the evaluation of the synthesized columns contained $0.5 \mu \mathrm{L} / \mathrm{mL}$ toluene and $0.5 \mathrm{mg} / \mathrm{mL}$ phenylalanine, tryptophan, and histidine. The concentration of other amino acids in the sample mixture was $1 \mathrm{mg} / \mathrm{mL}$ of each.

\section{Results and Discussion}

\subsection{Separation of Amino Acids on Monolithic Silica Capillary Columns_Plain Silica vs. Zwitterionic Stationary Phase}

Closely related structures of amino acids require highly selective stationary phases to achieve successful chromatographic separation under isocratic conditions. Figure 1a shows that a non-functionalized silica monolithic column has poor separation selectivity to amino acids under HILIC conditions. A better selectivity for amino acids was achieved on the zwitterionic column (Figure 1b) prepared by the modification procedure as described in [27], where a solution of MSA monomer at a concentration of $15 \mathrm{mg} / \mathrm{mL}$ and AIBN at a concentration of $0.45 \mathrm{mg} / \mathrm{mL}$ in methanol $(30 \%, v / v)$ and xylenes $(70 \%, v / v)$ was used for modification of the silica monolith. The reaction 
proceeded at $80^{\circ} \mathrm{C}$ for $3 \mathrm{~h}$. The retention of all amino acids was slightly improved compared to plain silica monoliths, although the pair of valine/tyrosine was not resolved under the aforementioned conditions. Nevertheless, the analysis was fast: the total analysis time did not exceed 6 min; see Figure $1 \mathrm{~b}$. On the other hand, the quality of separation was still not comparable to the previously published results for the gradient separation of amino acids on commercial particle packed analytical columns $[30,31]$.

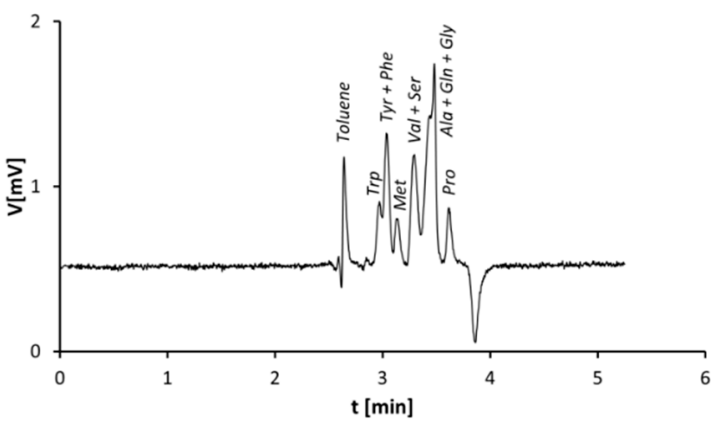

(a)

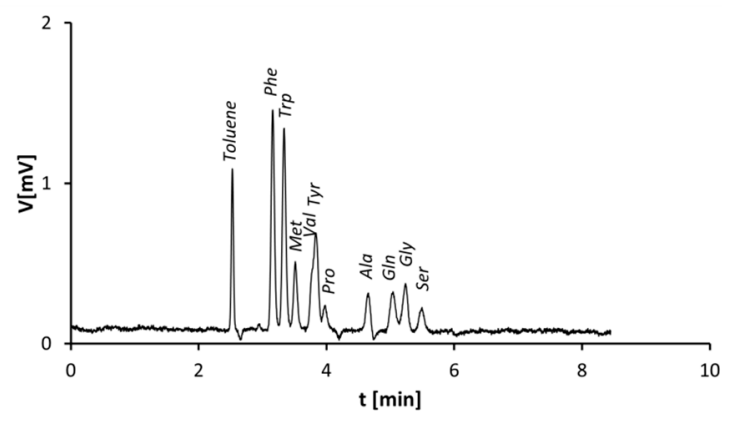

(b)

Figure 1. HILIC separation of ten amino acids. (a) plain silica monolithic capillary column; (b) MSA monolithic capillary column prepared according to the literature [27]. Operating conditions: columns $150 \times 0.1 \mathrm{~mm}$; mobile phase: $75 \% \mathrm{ACN}, 25 \% 25 \mathrm{mmol} / \mathrm{L}$ ammonium acetate at $\mathrm{pH} 4.5$; flow rate $500 \mathrm{~nL} / \mathrm{min}$; UV detection at $210 \mathrm{~nm}$.

\subsection{Capillary Columns Modified by the Stepwise Modification Procedure}

To improve the retention and selectivity of the zwitterionic stationary phase, a technique involving the creation of multiple polymer coating layers on the silica monolith was utilized. Compared to the previously published preparation method [27], the solution containing four times higher concentration of MSA $(60 \mathrm{mg} / \mathrm{mL})$ was used to modify silica monolithic columns. Each coating was created by flushing of the capillary column by MSA solution for $1.5 \mathrm{~h}$; see Section 2.3 for details. The quality of the resulting stationary phase created on the monolithic silica surface was evaluated through the retention of uracil. Although uracil is not strongly retained under the elution conditions employed. Rather, it serves as an example to illustrate how the retention of it indeed increases as a function of each modification. The variation in retention of uracil between individual modification steps is low, as reflected by the values of retention factor of uracil, $k_{\text {uracil }}$, listed in Table 1 . The monolithic column containing four polymer coating layers of MSA shows a 3.5 times greater value of $k_{\text {uracil }}$ than the column after the first modification step (1 coating layer) and 11-fold greater value of $k_{\text {uracil }}$ than plain silica monolithic column.

Table 1. The total porosity, retention factors, and efficiency of prepared monolithic columns.

\begin{tabular}{cccc}
\hline Monolith & Total Porosity $\boldsymbol{\varepsilon}_{\boldsymbol{T}}$ & $\boldsymbol{k}_{\text {uracil }}$ & $\boldsymbol{N}_{\text {uracil }}$ \\
\hline Silica & 0.945 & 0.04 & 180,200 \\
1st modification & 0.916 & 0.13 & 176,020 \\
2nd modification & 0.836 & 0.21 & 169,170 \\
3rd modification & 0.739 & 0.31 & 155,720 \\
4th modification & 0.669 & 0.45 & 146,870 \\
$k_{\text {uracil }}$-retention factor of uracil, $N_{\text {uracil }}$-number of theoretical plates per meter.
\end{tabular}

Data also shows that the retention factor of uracil increases with an increasing number of polymer coating layers created on the monolithic silica surface, while the column efficiency expressed as a plate count per meter decreases in the same manner. The plain silica monolithic capillary column showed efficiency of 180,200 theoretical plates/m, but the first MSA coating decreased this number to 176,020 
theoretical plates $/ \mathrm{m}$. The column modified by four coating layers of MSA showed reduced efficiency of 146,870 theoretical plates $/ \mathrm{m}$, which corresponds to the theoretical plate height of $6.8 \mu \mathrm{m}$.

The total porosity of the column, $\varepsilon_{T}$, was calculated as the ratio of the hold-up volume of the column reduced by a volume of the capillary connecting the column outlet with a UV detection cell, and the geometric volume of the empty fused silica capillary used to prepare the column. The volume of capillary connecting the column and the detector cell cannot be neglected with respect to the geometrical volume of the column $(0.11 \mu \mathrm{L}$ vs. $1.18 \mu \mathrm{L})$; see Section 2.2. The hold-up volume of the column was obtained from the volumetric flow rate of the mobile phase $(75 \% v / v$ ACN in $25 \mathrm{mmol} / \mathrm{L}$ ammonium acetate at $\mathrm{pH} 4.5$ ), and the column hold-up time $t_{0}$ determined using toluene. $\varepsilon_{T}$ reached a value of 0.95 for the plain silica monolithic column. The first polymer coating layer created on the silica monolith reduced the value of $\varepsilon_{T}$ by $3 \%$, but the next modification by MSA caused a decrease in the column porosity by approximately $9-11 \%$; see Table 1 . The $k_{\text {uracil }}$ increased simultaneously with the reduced porosity of the monolithic column. Further modification was not performed due to high backpressure of the prepared column. Figure 2a shows a cross section of the prepared plain silica monolithic column, which was further modified by a MSA coating. Comparison of the plain and the MSA modified monoliths is depicted in Figure $2 b$,c. Figure $2 b$ shows the detail of the unmodified silica with the bi-modal structure typical for the silica monolith. The structure of the monolith significantly changed when the modification procedure was repeated four times (Figure 2c). The nanopores are covered by a polymer coating of MSA, and the size of the through pores is lowered; changes in values of $\varepsilon_{T}$ and $k_{\text {uracil }}$ (Table 1 ) reflect these findings.

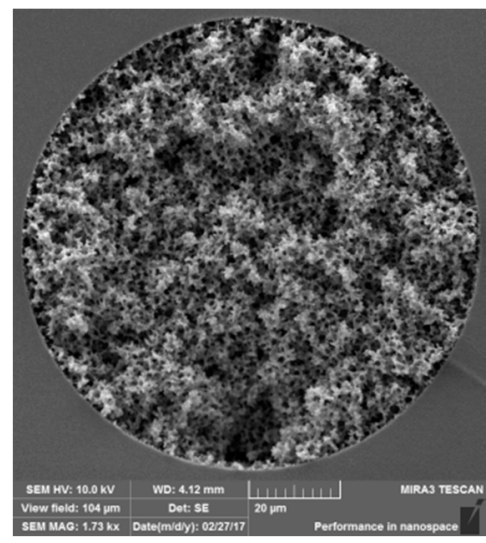

(a)

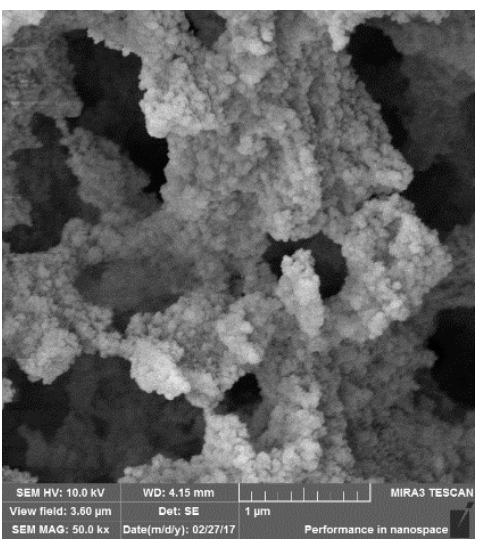

(b)

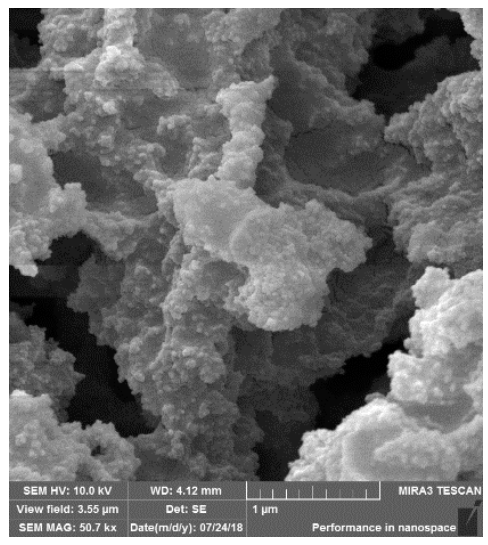

(c)

Figure 2. Scanning electron microphotographs of prepared monolithic columns. (a) detail of the plain silica monolithic capillary column; (b) unmodified monolithic silica skeleton; (c) monolithic silica skeleton modified by four coating layers of MSA.

Figure 3a confirms that the MSA monolithic capillary column with four polymer coating layers of MSA is suitable for efficient separation of the mixture containing fifteen amino acids under isocratic HILIC conditions. Amino acids were eluted from the column within $15 \mathrm{~min}$ when $25 \mathrm{mmol} / \mathrm{L}$ ammonium acetate ( $\mathrm{pH} 4.5)$ was used as a part of the mobile phase. The corresponding retention factors are listed in Table 2. Amino acids with hydrophobic side chains were the first to elute from the column according to the decreasing hydrophobicity. The column is able to separate compounds such as leucine and isoleucine differing in position of the methylene group, as was proven before for nucleosides [27]. In addition, proline and 4-hydroxy proline differing in the hydroxyl group were also well separated on this column.

Buffer concentration in the mobile phase affects the retention and chromatographic resolution of amino acids. A higher concentration of ammonium acetate in the mobile phase caused an increase in the retention of all amino acids except for positively charged histidine; see Table 2 and Figure 3. Histidine also co-eluted with glycine and glutamine when $25 \mathrm{mmol} / \mathrm{L}$ ammonium acetate was used 
as the aqueous part of the mobile phase (Figure 3a). Baseline separation of glutamine and glycine was obtained using the mobile phase containing five times lower concentration of ammonium acetate (Figure $3 b$ ) when the retention time of histidine was shifted to higher values.

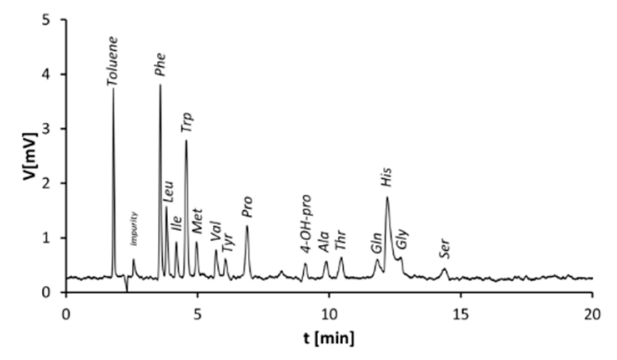

(a)

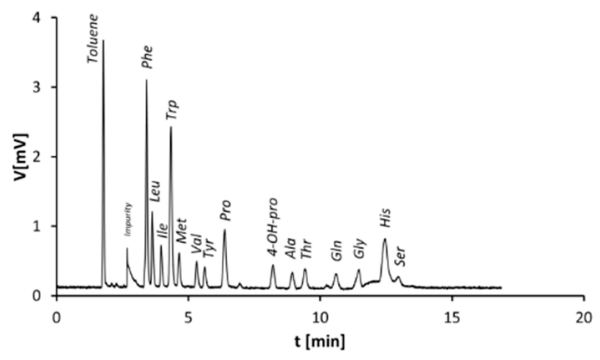

(b)

Figure 3. HILIC separation of fifteen amino acids on MSA monolithic capillary column. Operating conditions: column $150 \times 0.1 \mathrm{~mm}$; mobile phase: (a) $75 \% \mathrm{ACN}, 25 \% 25 \mathrm{mmol} / \mathrm{L}$ ammonium acetate at $\mathrm{pH} 4.5$; (b) $75 \% \mathrm{ACN}, 25 \% 5 \mathrm{mmol} / \mathrm{L}$ ammonium acetate at $\mathrm{pH} 4.5$; flow rate $500 \mathrm{~nL} / \mathrm{min}$; $\mathrm{UV}$ detection at $210 \mathrm{~nm}$.

Table 2. Effect of buffer concentration on retention factors of amino acids.

\begin{tabular}{ccc}
\hline Amino Acid & $\boldsymbol{k}_{5}{ }^{*}$ & $\boldsymbol{k}_{\mathbf{2 5}}{ }^{*}$ \\
\hline Phenylalanine & 0.92 & 0.99 \\
Leucine & 1.04 & 1.12 \\
Isoleucine & 1.23 & 1.33 \\
Tryptophan & 1.44 & 1.54 \\
Methionine & 1.61 & 1.76 \\
Valine & 1.98 & 2.17 \\
Tyrosine & 2.13 & 2.37 \\
Proline & 2.56 & 2.83 \\
4-Hydroxy proline & 3.59 & 4.06 \\
Alanine & 4.01 & 4.51 \\
Threonine & 4.30 & 4.82 \\
Glutamine & 4.97 & 5.58 \\
Histidine & 6.03 & 5.79 \\
Glycine & 5.46 & 6.07 \\
Serine & 6.29 & 7.00
\end{tabular}

* Retention factors $k_{5}$ in mobile phase $75 \% \mathrm{ACN}, 25 \% 5 \mathrm{mmol} / \mathrm{L}$ ammonium acetate at $\mathrm{pH} 4.5 .{ }^{* *}$ Retention factors $k_{25}$ in mobile phase $75 \% \mathrm{ACN}, 25 \% 25 \mathrm{mmol} / \mathrm{L}$ ammonium acetate at $\mathrm{pH} 4.5$.

\section{Conclusions}

The capillary monolithic columns prepared by the stepwise modification procedure enabled the separation of fifteen amino acids under isocratic HILIC conditions. This is advantageous when a large number of samples are to be processed, e.g., in the areas of proteomics, metabolomics, or foodomics. The total analysis time was reduced compared to the gradient elution where the re-equilibration time of the column increases the overall time required for analysis. The zwitterionic columns prepared by the stepwise modification procedure using the solution of the MSA monomer allowed a better separation of amino acids than the plain silica monolithic column, as well as the column with one polymer coating layer of MSA. Concentration of the buffer in the mobile phase makes it possible to manipulate the retention characteristics of native amino acids, i.e., a lower buffer concentration in the mobile phase caused an increase in the chromatographic resolution of amino acids such as glutamine, glycine, and histidine.

Author Contributions: Conceptualization, D.M.; Investigation, D.M. and J.P.; Methodology, D.M. and J.P.; Writing-original draft, D.M. 
Funding: This research was funded by the Czech Science Foundation (Project No. 16-03749S), by the Ministry of the Interior of the Czech Republic (Project No. VI20172020069), and by the Czech Academy of Sciences (institutional support RVO:68081715).

Conflicts of Interest: The authors declare no conflict of interest.

\section{References}

1. Song, Y.; Xu, C.; Kuroki, H.; Liao, Y.; Tsunoda, M. Recent trends in analytical methods for the determination of amino acids in biological samples. J. Pharm. Biomed. Anal. 2018, 147, 35-49. [CrossRef]

2. Gar, C.; Rottenkolber, M.; Prehn, C.; Adamski, J.; Seissler, J.; Lechner, A. Serum and plasma amino acids as markers of prediabetes, insulin resistance, and incident diabetes. Crit. Rev. Clin. Lab. Sci. 2018, 55, 21-32. [CrossRef] [PubMed]

3. Begou, O.; Gika, H.G.; Wilson, I.D.; Theodoridis, G. Hyphenated MS-based targeted approaches in Metabolomics. Analyst 2017, 142, 3079-3100. [CrossRef] [PubMed]

4. Manig, F.; Kuhne, K.; von Neubeck, C.; Schwarzenbolz, U.; Yue, Z.; Kessler, B.M.; Pietzsch, J.; Kunz-Schughart, L.A. The why and how of amino acid analytics in cancer diagnostics and therapy. J. Biotechnol. 2017, 242, 30-54. [CrossRef] [PubMed]

5. Wahl, O.; Holzgrabe, U. Amino acid analysis for pharmacopoeial purposes. Talanta 2016, 154, $150-163$. [CrossRef] [PubMed]

6. Baghdady, Y.Z.; Schug, K.A. Review of in situ derivatization techniques for enhanced bioanalysis using liquid chromatography with mass spectrometry. J. Sep. Sci. 2016, 39, 102-114. [CrossRef] [PubMed]

7. Marrubini, G.; Appelblad, P.; Maietta, M.; Papetti, A. Hydrophilic interaction chromatography in food matrices analysis: An updated review. Food Chem. 2018, 257, 53-66. [CrossRef] [PubMed]

8. Šesták, J.; Moravcová, D.; Kahle, V. Instrument platforms for nano liquid chromatography. J. Chromatogr. A 2015, 1421, 2-17. [CrossRef] [PubMed]

9. Nazario, C.E.D.; Silva, M.R.; Franco, M.S.; Lanças, F.M. Evolution in miniaturized column liquid chromatography instrumentation and applications: An overview. J. Chromatogr. A 2015, 1421, 18-37. [CrossRef] [PubMed]

10. Novotny, M.V. Development of capillary liquid chromatography: A personal perspective. J. Chromatogr. A 2017, 1523, 3-16. [CrossRef] [PubMed]

11. Yi, L.; Piehowski, P.D.; Shi, T.; Smith, R.D.; Qian, W.J. Advances in microscale separations towards nanoproteomics applications. J. Chromatogr. A 2017, 1523, 40-48. [CrossRef] [PubMed]

12. Fanali, S. An overview to nano-scale analytical techniques: Nano-liquid chromatography and capillary electrochromatography. Electrophoresis 2017, 38, 1822-1829. [CrossRef] [PubMed]

13. Liu, Y.; Wang, W.; Jia, M.; Liu, R.; Liu, Q.; Xiao, H.; Li, J.; Xue, Y.; Wang, Y.; Yan, C. Recent advances in microscale separation. Electrophoresis 2018, 39, 8-33. [CrossRef] [PubMed]

14. Svec, F.; Lv, Y.Q. Advances and recent trends in the field of monolithic columns for chromatography. Anal. Chem. 2015, 87, 250-273. [CrossRef] [PubMed]

15. Ikegami, T.; Tanaka, N. Recent progress in monolithic silica columns for high-speed and high-selectivity separations. Annu. Rev. Anal. Chem. 2016, 9, 317-342. [CrossRef] [PubMed]

16. Eeltink, S.; Wouters, S.; Dores-Sousa, J.L.; Svec, F. Advances in organic polymer-based monolithic column technology for high-resolution liquid chromatography-mass spectrometry profiling of antibodies, intact proteins, oligonucleotides, and peptides. J. Chromatogr. A 2017, 1498, 8-21. [CrossRef] [PubMed]

17. Rathnasekara, R.; Khadka, S.; Jonnada, M.; El Rassi, Z. Polar and nonpolar organic polymer-based monolithic columns for capillary electrochromatography and high-performance liquid chromatography. Electrophoresis 2017, 38, 60-79. [CrossRef] [PubMed]

18. Dinga, X.; Yanga, J.; Dong, Y. Advancements in the preparation of high-performance liquid chromatographic organic polymer monoliths for the separation of small-molecule drugs. J. Pharm. Anal. 2018, 8, 75-78. [CrossRef] [PubMed]

19. Nakanishi, K.; Soga, N. Phase separation in silica sol-gel system containing polyacrylic acid I. Gel formation behavior and effect of solvent composition. J. Non-Cryst. Solids 1992, 139, 1-13. [CrossRef] 
20. Minakuchi, H.; Nakanishi, K.; Soga, N.; Ishizuka, N.; Tanaka, N. Octadecylsilylated porous silica rods as separation media for reversed-phase liquid chromatography. Anal. Chem. 1996, 68, 3498-3501. [CrossRef] [PubMed]

21. Núñez, O.; Nakanishi, K.; Tanaka, N. Preparation of monolithic silica columns for high-performance liquid chromatography. J. Chromatogr. A 2008, 1191, 231-252. [CrossRef] [PubMed]

22. Ou, J.; Liu, Z.; Wang, H.; Lin, H.; Dong, J.; Zou, H. Recent development of hybrid organic-silica monolithic columns in CEC and capillary LC. Electrophoresis 2015, 36, 62-75. [CrossRef] [PubMed]

23. Viklund, C.; Sjögren, A.; Irgum, K.; Nes, I. Chromatographic interactions between proteins and sulfoalkylbetaine-based zwitterionic copolymers in fully aqueous low-salt buffers. Anal. Chem. 2001, 73, 444-452. [CrossRef] [PubMed]

24. Jiang, Z.; Smith, N.W.; Ferguson, P.D.; Taylor, M.R. Hydrophilic interaction chromatography using methacrylate-based monolithic capillary column for the separation of polar analytes. Anal. Chem. 2007, 79, 1243-1250. [CrossRef] [PubMed]

25. Urban, J.; Škeříková, V.; Jandera, P.; Kubíčková, R.; Pospíšilová, M. Preparation and characterization of polymethacrylate monolithic capillary columns with dual hydrophilic interaction reversed-phase retention mechanism for polar compounds. J. Sep. Sci. 2009, 32, 2530-2543. [CrossRef] [PubMed]

26. Wohlgemuth, J.; Karas, M.; Jiang, W.; Hendriks, R.; Andrecht, S. Enhanced glyco-profiling by specific glycopeptide enrichment and complementary monolithic nano-LC (ZIC-HILIC/RP18e)/ESI-MS analysis. J. Sep. Sci. 2010, 33, 880-890. [CrossRef] [PubMed]

27. Moravcová, D.; Planeta, J.; Kahle, V.; Roth, M. Zwitterionic silica-based monolithic capillary columns for isocratic and gradient hydrophilic interaction liquid chromatography. J. Chromatogr. A 2012, 1270, 178-185. [CrossRef] [PubMed]

28. Lin, H.; Ou, J.; Zhang, Z.; Dong, J.; Wu, M.; Zou, H. Facile preparation of zwitterionic organic-silica hybrid monolithic capillary column with an improved "one-pot" approach for hydrophilic-interaction liquid chromatography (HILIC). Anal. Chem. 2012, 84, 2721-2728. [CrossRef] [PubMed]

29. Moravcová, D.; Planeta, J.; King, A.W.T.; Wiedmer, S.K. Immobilization of a phosphonium ionic liquid on a silica monolith for hydrophilic interaction chromatography. J. Chromatogr. A 2018, 1552, 53-59. [CrossRef] [PubMed]

30. Konieczna, L.; Pyszka, M.; Okońska, M.; Niedźwiecki, M.; Bączek, T. Bioanalysis of underivatized amino acids in non-invasive exhaled breath condensate samples using liquid chromatography coupled with tandem mass spectrometry. J. Chromatogr. A 2018, 1542, 72-81. [CrossRef] [PubMed]

31. Schiesel, S.; Lämmerhofer, M.; Lindner, W. Multitarget quantitative metabolic profiling of hydrophilic metabolites in fermentation broths of $\beta$-lactam antibiotics production by HILIC-ESI-MS/MS. Anal. Bioanal. Chem. 2010, 396, 1655-1679. [CrossRef] [PubMed]

(c) 2018 by the authors. Licensee MDPI, Basel, Switzerland. This article is an open access article distributed under the terms and conditions of the Creative Commons Attribution (CC BY) license (http:/ / creativecommons.org/licenses/by/4.0/). 